\title{
Experimental Validation of Froude-Modeling-Based Physical Scaling of Water Mist Cooling of Enclosure Fires
}

\author{
HONG-ZENG YU, XIANGYANG ZHOU and BENJAMIN D. DITCH \\ FM Global \\ 1151 Boston-Providence Turnpike \\ Norwood, MA 02062
}

\begin{abstract}
Fire suppression experiments were conducted in two geometrically similar enclosures of 3-to-1 ratio under fire products collectors to quantify water mist cooling of propane fires, to evaluate the scaling applicability of Froude modeling for water mist cooling of enclosure fires. The parameters considered in the evaluation were: enclosure size, door opening size, water mist spray condition, fire size, fire location and fire-

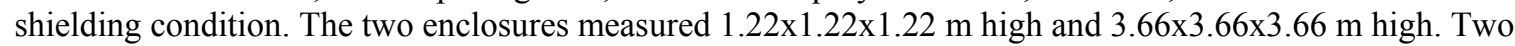
door opening sizes were tested for each enclosure: $0.30 \times 0.61 \mathrm{~m}$ high and $0.61 \times 0.61 \mathrm{~m}$ high for the Scale- 1 enclosure and $0.91 \times 1.83 \mathrm{~m}$ high and $1.83 \times 1.83 \mathrm{~m}$ high for the Scale-3 enclosure. Propane fires were established on $0.3-\mathrm{m}$ and $0.91-\mathrm{m}$ diameter burners respectively for the two scaled enclosures. Four corresponding pairs of propane supply rates were selected according to the scaling requirement, producing 10 to $50 \mathrm{~kW}$ at Scale-1 and 150 to $800 \mathrm{~kW}$ at Scale-3. Two water mist nozzles operating respectively at 13.8 and 43.7 bar were used to produce the water mist sprays in the two enclosures. In each enclosure, nine nozzles were arranged in a $3 \times 3$ pattern at the ceiling level with equal nozzle-to-nozzle and nozzle-to-wall spacing. The results show that Froude modeling can be used to scale water mist cooling of enclosure fires under the present experimental conditions.
\end{abstract}

KEYWORDS: Froude modeling, water mist, cooling, suppression, compartment fires

\section{NOMENCLATURE LISTING}

$\begin{array}{ll}A & \text { area } \\ C & \text { specific heat } \\ C_{D} & \text { drag coefficient } \\ d & \text { water drop diameter } \\ F & \text { drag force } \\ F r & \text { Froude number } \\ F_{1,2} & \text { view factor } \\ g & \text { gravitational acceleration } \\ h & \text { heat transfer coefficient } \\ k & \text { constant } \\ L & \text { characteristic dimension } \\ m & \text { mass } \\ \dot{m} & \text { mass flow rate } \\ \dot{q}^{\prime \prime} & \text { heat flux } \\ \dot{Q} & \text { energy rate } \\ R e & \text { Reynolds number } \\ t & \text { time } \\ T & \text { temperature } \\ \vec{u} & \text { velocity vector } \\ u & \text { scalar value of velocity vector } \\ x & \text { constant }\end{array}$

\begin{tabular}{|c|c|}
\hline \multicolumn{2}{|l|}{ Greek } \\
\hline$\rho$ & density \\
\hline$v$ & kinematic viscosity \\
\hline \multicolumn{2}{|c|}{ subscripts } \\
\hline$a m b$ & ambient \\
\hline burner & burner \\
\hline chem & chemical heat \\
\hline $\operatorname{conv}$ & convective heat \\
\hline$d$ & water drop \\
\hline duct & FPC duct \\
\hline$g$ & gas \\
\hline$i$ & object index \\
\hline in & inlet \\
\hline open & opening \\
\hline out & outlet \\
\hline $\mathrm{rad}$ & radiation \\
\hline runoff & water runoff \\
\hline shield & burner shield \\
\hline surface & wall surface \\
\hline water & water \\
\hline$\infty$ & ambient \\
\hline
\end{tabular}

\section{INTRODUCTION}

The complex phenomenon of water mist fire suppression has been understood qualitatively [1], but not quantitatively [2]. Although numerical simulations of water mist fire suppression, based on either field modeling or global modeling, have been making progress and are valuable in providing engineering 
guidance, these simulation models currently are not fully validated. Thus, the fire protection industry still relies on the tried-but-true, yet expensive, large-scale testing approach to develop water mist fire protection systems $[3,4]$. This makes the development of many potential applications economically prohibitive. Before computer modeling is sufficiently reliable, a possible solution is a proven physical scaling protocol that can be used to assess important fire suppression mechanisms in a scaled-down facility. As a result, the development of new applications can be carried out in a much more cost-effective manner.

In the 1970s, Heskestad proposed a set of scaling relationships for the interaction of water spray and fire plume in geometrically similar spaces [5]. These scaling relationships are based on the Froude-modeling concept by maintaining in different scales a constant Froude number in the buoyancy-induced gas flow, preserving the dynamic interaction characteristics of water drops with the gas flow, and conserving scalar variables in the physical domain. The scaling relationships proposed by Heskestad are based on water sprays with a significant inertia relative to the gas flow: a high drop Reynolds number condition. This condition leads to the requirement that drop size be scaled with $1 / 2$-power of length scale. However, for typical total flooding applications of water mist in enclosures, the water mist tends to move closely with the circulating gas current, leading to low drop Reynolds number situations. Furthermore, the Froude modeling was performed strictly from the view point of fluid mechanics in open space. As a result, not considered in the modeling for the fire-related variables are heat radiation, confined space effect, and surface effect on fuel pyrolysis. Before applying these scaling relationships to general fire protection problems, it is imperative that the relationships be examined for: 1) the impact of drop size (i.e. the effect of drop Reynolds number); 2) enclosure effect; 3) radiation effect; and 4) the effect of combustible types.

The effect of drop size on the scaling relationships has been investigated theoretically by $\mathrm{Yu}$ [6]. The finding from this investigation indicated that the relationships developed for high Reynolds number conditions could be broadly extended to low Reynolds number conditions, except that the drop size should be scaled with the 1/4-power of length scale, instead of the 1/2-power found for high Reynolds number conditions [5]. The drop-size scaling requirement for low drop Reynolds number conditions was later confirmed with a series of fire cooling experiments [7]. These experiments, conducted under fire products collectors over three different scales up to 9-to-1 scale ratios, quantified water mist cooling of fires in open space. Three methane burners with 1,3 and 9 scale ratios were used to release pre-determined fuel flow rates and three sets of corresponding water mist nozzles were selected to produce water mist discharges meeting the scaling requirements for low drop Reynolds number conditions. For experiments conducted in each scale, four water mist nozzles were positioned equidistant to and around the burner and in the plane of the burner surface. The low drop Reynolds number condition was obtained by directing the water mist sprays upward in co-flow orientations with the fire plume so that the delivery of water mist to the flame was mainly by entrainment. The experimental results showed that water mist cooling of fire gases can be scaled as expected from the relationships pertaining to the low drop Reynolds number condition.

This paper presents an evaluation of the applicability of Froude modeling for water mist cooling of enclosure fires. A review of the general scaling relationships is first presented below. It is then followed by the description of the experiments conducted in this study and the results obtained from these experiments.

\section{FROUDE-MODELING-BASED SCALING RELATIONSHIPS FOR FIRE SUPPRESSION}

The processes involved in the fire suppression by water sprays consist of: 1) spray formation; 2) water drop transport from the discharging nozzles to the fire and fuel surfaces; 3 ) water transport on and in the fuel; and 4) fire suppression or extinguishment through direct or indirect interactions between fire and water application. The above processes are more or less associated with or affected by the interaction of fire plume and water sprays.

If we can properly scale the interaction of fire plume and water sprays, we can reproduce the spray pattern, fire gas flow field, and vaporization process of water drops before they land on solid surfaces. To do this, we need to first address the scaling of spray formation. The reproduced spray pattern provides the same water distribution in the fire environment for fire suppression. Since the vaporization process is reproduced, we can reproduce the thermal and inerting conditions in the fire environment. So it is expected that the fire suppression result can be reasonably reproduced if we can scale the water-spray-fire-plume interaction.

Before presenting the general scaling relationships, we need to first define two dimensionless parameters: 
the Reynolds number of the drop motion and the Froude number of the gas flow. The drop Reynolds number is defined as

$\operatorname{Re}_{d}=\frac{d\left|\vec{u}_{d}-\vec{u}_{g}\right|}{v_{g}}$,

where $d$ and $\vec{u}_{d}$ are the drop diameter and drop velocity vector, and $\vec{u}_{g}$ and $v_{\mathrm{g}}$ are the gas velocity vector and gas kinematic viscosity, respectively. The Froude number is defined as

$F r=\frac{\rho_{g} u_{g}^{2}}{g L\left(\rho_{\infty}-\rho_{g}\right)}$,

where $\rho_{g}$ and $\rho_{\infty}$ are fire gas density and ambient air density, respectively, $\mathrm{g}$ is gravitational acceleration, $\mathrm{L}$ is the characteristic dimension of the fire environment, and $u_{g}$ is the scalar value of the gas velocity vector $\vec{u}_{g}$.

The principle of Froude modeling is to conserve: 1) the Froude number of gas flow in different scales; 2) the momentum transfer characteristics between water drops and gas medium; 3) the drop vaporization characteristics, and 4) the scalar properties, such as temperature and concentrations, in the control volume. The momentum exchange between water drops and gas medium is governed by the drag force resulting from the velocity difference between water drop motion and gas flow:

$F=\frac{1}{2} C_{D} A_{d} \rho_{g}\left|\vec{u}_{d}-\vec{u}_{g}\right|\left(\vec{u}_{d}-\vec{u}_{g}\right)$,

where $C_{D}$ and $A_{d}$ are the drag coefficient and the frontal area of a water drop, respectively.

The drag coefficient for a range of Reynolds numbers can be expressed with a power-law function such as

$\mathrm{C}_{\mathrm{D}}=\frac{k}{\operatorname{Re}_{\mathrm{d}}^{\mathrm{x}}}$,

where $k$ and $x$ are constants that give the best representation of $\mathrm{C}_{\mathrm{D}}$ in the designated range of drop Reynolds numbers.

The derivation of the general scaling relationships based on Froude modeling has been described in great details in Ref. [6]. Table 1 below summarizes the general scaling relationships for any drop Reynolds number and the relationships specific for the conditions of $\operatorname{Re}_{d} \leq 1$ and $10<\operatorname{Re}_{d} \leq 500$. The expressions shown in the first and second columns can be obtained by substituting 1 and $1 / 2$ for $\mathrm{x}$, respectively. As shown, all of the scaling relationships are identical for different ranges of Reynolds numbers, except for the scaling requirements for drop number density and drop size.

To evaluate the Froude modeling of water mist fire suppression in enclosures, a series of experiments was conducted in this study under the condition of $\operatorname{Re}_{\mathrm{d}} \leq 1$.

\section{FIRE SUPPRESSION EXPERIMENTS}

Two geometrically similar enclosures with a 3-to-1 scale ratio were constructed for the fire suppression experiments. The parameters considered in the experiments were: enclosure size, door opening size, water mist spray characteristics, fire size, fire location and fire-shielding condition. To continuously measure the fire heat release rate, experiments were conducted under a $200-\mathrm{kW}$ or a $1-\mathrm{MW}$ capacity fire products collector (FPC) in the Calorimetry Laboratory at the FM Global Research Campus, located in West Glocester, Rhode Island.

\section{Test Enclosures}

The Scale-1 enclosure, shown in Fig. 1, measured 1.22x1.22x1.22 m high and the Scale-3 enclosure was $3.66 \times 3.66 \times 3.66 \mathrm{~m}$ high. Both enclosures were of a steel-framed structure, and lined with 1.2-mm and 3.4- 
Table 1. Scaling Relationships.

\begin{tabular}{|c|c|c|c|}
\hline Scaling Parameters & $\mathrm{Re}_{\mathrm{d}} \leq 1$ & $10<\mathrm{Re}_{\mathrm{d}} \leq 500$ & ${\mathrm{Any} \mathrm{Re}_{\mathrm{d}}}$ \\
\hline Drag Coefficient & $\propto \mathrm{Re}_{\mathrm{d}}{ }^{-1}$ & $\propto \mathrm{Re}_{\mathrm{d}}{ }^{-1 / 2}$ & $\propto \mathrm{Re}_{\mathrm{d}}{ }^{-x}$ \\
\hline Dimension & $\mathrm{L}^{1}$ & $\mathrm{~L}^{1}$ & $\mathrm{~L}^{1}$ \\
\hline Time & $\mathrm{L}^{1 / 2}$ & $\mathrm{~L}^{1 / 2}$ & $\mathrm{~L}^{1 / 2}$ \\
\hline $\begin{array}{c}\text { All Scalar Parameters } \\
\text { except Drop Number Density }\end{array}$ & $\mathrm{L}^{0}$ & $\mathrm{~L}^{0}$ & $\mathrm{~L}^{(3 x-6) /(2+2 x)}$ \\
\hline Drop Number Density & $\mathrm{L}^{-3 / 4}$ & $\mathrm{~L}^{-3 / 2}$ & $\mathrm{~L}^{1 / 2}$ \\
\hline Velocity & $\mathrm{L}^{1 / 2}$ & $\mathrm{~L}^{1 / 2}$ & $\mathrm{~L}^{5 / 2}$ \\
\hline Ventilation rate & $\mathrm{L}^{5 / 2}$ & $\mathrm{~L}^{5 / 2}$ & $\mathrm{~L}^{5 / 2}$ \\
\hline $\begin{array}{c}\text { Fire Convective Heat Release } \\
\text { Rate }\end{array}$ & $\mathrm{L}^{5 / 2}$ & $\mathrm{~L}^{5 / 2}$ & $\mathrm{~L}^{5 / 2}$ \\
\hline Total Water Discharge Rate & $\mathrm{L}^{5 / 2}$ & $\mathrm{~L}^{5 / 2}$ & $\mathrm{~L}^{1 / 2}$ \\
\hline Water Flux & $\mathrm{L}^{1 / 2}$ & $\mathrm{~L}^{5 / 2}$ & $\mathrm{~L}^{(2-x) /(2+2 x)}$ \\
\hline Total Cooling Rate & $\mathrm{L}^{5 / 2}$ & $\mathrm{~L}^{1 / 2}$ & \\
\hline Drop Size & $\mathrm{L}^{1 / 4}$ & &
\end{tabular}
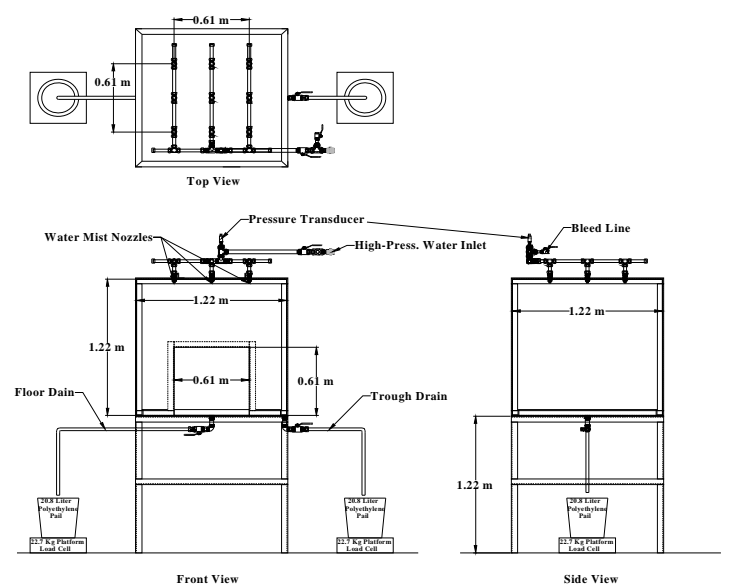

Fig. 1. A schematic of the Scale-1 test enclosure.

$\mathrm{mm}$ thick steel sheets, respectively. Both enclosures were completely insulated with 51-mm thick, aluminum-foil-faced insulation boards with a density of $96.2 \mathrm{~kg} / \mathrm{m}^{3}$ and a thermal conductivity of 0.018 $\mathrm{W} / \mathrm{m} / \mathrm{K}$. As shown in Fig. 1, to measure the amount of sensible heat carried in the water falling on the enclosure surfaces, two drainage openings were provided: one drain was located near the floor center and the other was at the mid-point base of one of the enclosure walls. To segregate water run-offs from walls and from water mist falling directly on the floor, a continuous channel, $57 \mathrm{~mm}$ wide by $38 \mathrm{~mm}$ deep, was provided along the base of the walls and the perimeter of the door opening. For the Scale- 3 enclosure, a similar channel arrangement was made but three floor drains were provided to speed up the drainage: one near the floor center and each of the other two was centered to and abutting one of two opposite walls. To prevent water puddles from forming on the Scale- 3 enclosure floor, the floor was pitched about $1^{\circ}$ toward its center. All the drainage openings were $51 \mathrm{~mm}$ in diameter and connected to $25 \mathrm{~mm}$ ID tubes with threaded reduction bushings. Below each bushing a U-trap made of $25-\mathrm{mm}$ tubing was installed, in which the sensing point of a 26-gage, inconel-sheathed, Type-K thermocouple was positioned near the bottom of the U-trap. The water run-offs from the walls and from the floor were directed to two holding containers and their weights were measured using load cell platforms. For the Scale-1 enclosure, two Rice Lake Model 8M1818S0 load cell platforms with a capacity of $22.7 \mathrm{~kg}$ were used. For the Scale- 3 enclosure, the Rice Lake load cell platform was used to measure the wall run-off, and a GSE Model 4440 load cell platform with a capacity of $181.6 \mathrm{~kg}$ was used to measure the water drainage from the floor. 
To evaluate the effect of natural ventilation on fire extinguishment under water mist applications, experiments were conducted with two door opening sizes for each enclosure. For the Scale-1 enclosure, the door opening measured $0.30 \times 0.61 \mathrm{~m}$ high or $0.61 \times 0.61 \mathrm{~m} \mathrm{high}$; for the Scale- 3 enclosure, the door opening was $0.91 \times 1.83 \mathrm{~m}$ high or $1.83 \times 1.83 \mathrm{~m}$ high. To prevent water on the floor from spilling over the door base, a lip of 13 and $44 \mathrm{~mm}$ high was provided at the door opening base for the Scale-1 and Scale- 3 enclosures, respectively.

\section{Enclosure Instrumentation}

Each enclosure was instrumented to measure the radiant heat flux from the door opening, heat flux into the enclosure surface, enclosure surface temperature, thermal stratification in the enclosure, and gas concentrations in the enclosure.

A wide-angle radiometer was used to measure the heat flux radiating from the door opening. The radiometer had a Dexter Model M5 thin film-based thermopile detector, which had a flat spectral response in the entire thermal radiation range ranging from $100 \mathrm{~nm}$ to $100 \mu \mathrm{m}$. The sensor was installed in a cylindrical water-cooled copper housing connected to a shutter assembly whose rectangular opening could be adjusted manually. At a distance from the door opening, the radiometer was leveled and centered to the door opening, and its field of view was aligned to the perimeter of the door opening using a laser alignment beam.

The heat transfer to the enclosure surfaces was measured using thin film heat flux sensors (Omega Model HFS-4 or Rdf Model HFS-C) and 26-gage Type-K thermocouples. The Rdf and Omega sensors were used respectively with the Scale-1 and Scale-3 enclosures. A heat sink compound (Dow Corning 340 silicone heat sink) was applied between the heat flux sensors and enclosure surfaces to ensure good thermal contact. The heat flux sensors were secured to the enclosure surfaces by applying aluminum foil tape along the sensor perimeter. The thermocouples were installed at designated locations on the outer steel surfaces of the enclosure. Assuming that the steel temperature between the inner and outer surfaces is reasonably uniform, the heat flux to the enclosure surface can be calculated with

$\dot{q}^{\prime \prime}=\rho \delta C \frac{d T}{d t}$,

where $\rho\left(7834 \mathrm{~kg} / \mathrm{m}^{3}\right), \mathrm{C}\left(0.46 \mathrm{~kJ} / \mathrm{kg} /{ }^{\circ} \mathrm{C}\right)$ and $\delta$ are the density, heat capacity and thickness of the steel sheets used to construct the enclosures.

The thermal stratification inside each enclosure was measured using a thermocouple tree located near the left corner of the wall containing the door opening. Each thermocouple tree consisted of nine inconelsheathed, 26-gage, bare-bead thermocouples mounted on a vertical steel wire extending from the floor to the ceiling. To prevent direct water mist spray impingement, the thermocouple tree in each enclosure was protected with a vertical rectangular steel shield. In the Scale-1 enclosure, the thermocouples in the tree were positioned from 0.10 to $1.02 \mathrm{~m}$ below the ceiling; in the Scale-3 enclosure, the thermocouples were from 0.30 to $3.05 \mathrm{~m}$ below the ceiling.

Continuous gas sampling was performed to monitor the gas concentrations inside the enclosure using Rosemount Analytical Type MLT multi-gas analyzers. For the Scale-1 enclosure, a 6.4-mm diameter sampling port was located $0.10 \mathrm{~m}$ above the enclosure floor, near the far right corner from the door opening. For the Scale-3 enclosure, two individual sampling arrangements were provided. One was similar to that for the Scale-1 enclosure, except that the sampling port was about $0.30 \mathrm{~m}$ above the enclosure floor. The other sampling arrangement, near the other back corner, consisted of five 6.4-mm I.D. sampling ports positioned $0.61,1.22,1.83,2.44$ and $3.05 \mathrm{~m}$ above the enclosure floor. Before feeding the gases in each sampling line to the gas analyzers, the particulates and condensable gases in the gas stream were removed by a micro-filter, a desiccate and a cold trap. The concentrations of THC, oxygen, carbon dioxide and carbon monoxide in the enclosure were measured.

\section{Fire Products Collectors}

Figure 2 shows the 200-kW FPC positioned above the Scale-1 enclosure collecting the effluent from the door opening during an experiment. The following measurements were made continuously in both the 200- 


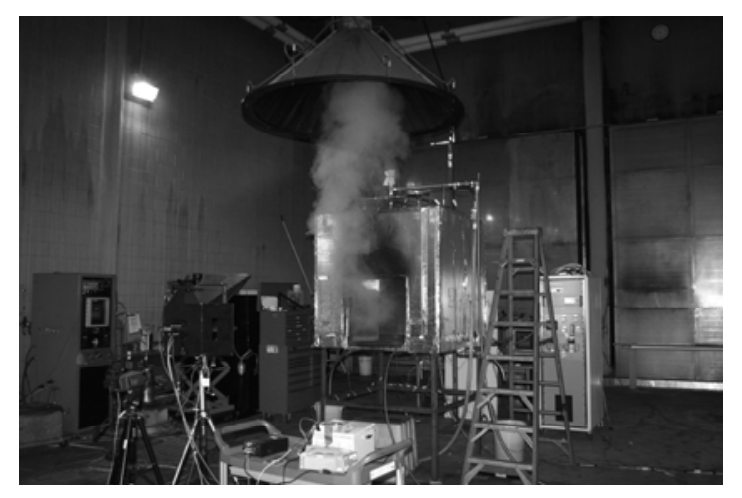

Fig. 2. A photographic illustration of the experimental setup of the Scale-1 enclosure and the 200-kW fire products collector.

kW and 1-MW FPCs: duct surface temperature, duct gas temperature, exhaust rate in the duct, and concentrations of $\mathrm{CO}_{2}, \mathrm{CO}, \mathrm{O}_{2}$, total hydrocarbon and water vapor in the exhaust stream, and the ambient temperature. The temperatures were measured with 30-gage K-type thermocouples. The gas concentrations were measured with respective Rosemount analyzers except for water vapor concentrations, which were measured with a Vaisala HMP235 sensor. The gas sampling line from the duct to the gas analyzers was heat traced to prevent condensation. Except for water vapor measurements, concentration measurements were corrected for time lag due to the transport time in the sampling line and the delay in the instruments [8]. However, it was determined that the impact of not correcting for the time delays of water vapor measurements was trivial since data analysis of water mist cooling was limited to steady-state durations. Based on the gas exhaust rate, gas concentrations and temperature in the FPC, FPC duct temperature, as well as the ambient conditions, the fire chemical heat release rate [9], convective heat carried in the exhaust and heat loss from the exhaust stream to the FPC duct could be calculated as described in the section of Data Analysis below.

\section{Water Mist Sprays and Nozzle Layout}

Two nozzles, designated as Nozzle A and Nozzle B, were used in the experiments to produce the desired spray pattern, drop sizes and water discharge rates for the Scale-1 and Scale-3 enclosures, respectively. These two nozzles generated solid-cone sprays. The downward water mist spray from each of theses two nozzles was measured at two elevations using a Phase-Doppler-Particle-Analyzer (PDPA): one slightly above the bottom of the conical spray region (i.e. transition plane) and the other at $10 \mathrm{~cm}$ below the transition plane. At each elevation, the water mist flux and local drop size distribution were mapped out across the entire spray. The gross drop size distributions of the water mist sprays were then calculated by weighting the local drop size distributions with the corresponding water mist fluxes and areas, as described in Ref. [10].

Table 2 gives the key spray properties of these two nozzles discharging at 13.8 and 41.4 bar, respectively. In the table, $\mathrm{d}_{\mathrm{v} 0.5}$ denotes the volumetric median drop diameter of the spray. Figure 3 shows the gross discharge volume fraction versus drop size normalized with $\mathrm{d}_{\mathrm{v} 0.5}$ at the transition plane for these two nozzles, which indicates that the gross drop size distributions of these two sprays are similar.

Nine nozzles were arranged in a $3 \times 3$ matrix in each enclosure with equal spacing between adjacent nozzles and between nozzles and adjacent walls. Using $25-\mathrm{mm}$ SS316 tubing and fittings, water was supplied to the nozzles from above the enclosure ceiling through drop tubes, as shown in Fig. 1. These drop tubes were connected to three branch lines with three on each line. The branch lines were in turn connected on-end to a manifold. The nozzles were secured underneath the enclosure ceiling using threaded fittings, resulting in nozzle tips being $32 \mathrm{~mm}$ below the ceiling.

A high pressure pump was used to supply the required discharge pressures and water discharge rates. The nozzle discharge pressure was monitored with a 69-bar rated pressure transducer (Trans-Metrics Model P21EA-10) at the junction of the manifold and the middle branch line above the enclosure. The water 
Table 2. Water Mist Spray Properties.

\begin{tabular}{|c|c|c|c|c|c|c|}
\hline \multirow{2}{*}{ Scale } & \multirow{2}{*}{ Nozzle } & \multirow{2}{*}{$\begin{array}{c}\text { Pressure } \\
\text { (bar) }\end{array}$} & $\begin{array}{c}\text { Spray } \\
\text { Cone Angle }\end{array}$ & \multicolumn{2}{|c|}{$\mathrm{d}_{\mathrm{v} 0.5}(\mu \mathrm{m})$} & $\begin{array}{c}\text { Discharge } \\
\text { Rate Per } \\
\text { Nozzle } \\
\text { (liter/min) }\end{array}$ \\
\hline 1 & $\mathrm{~A}$ & 13.8 & $60^{\circ}$ & 59 & 64 & 0.183 \\
\hline 3 & $\mathrm{~B}$ & 41.4 & $60^{\circ}$ & 91 & 90 & 2.782 \\
\hline
\end{tabular}

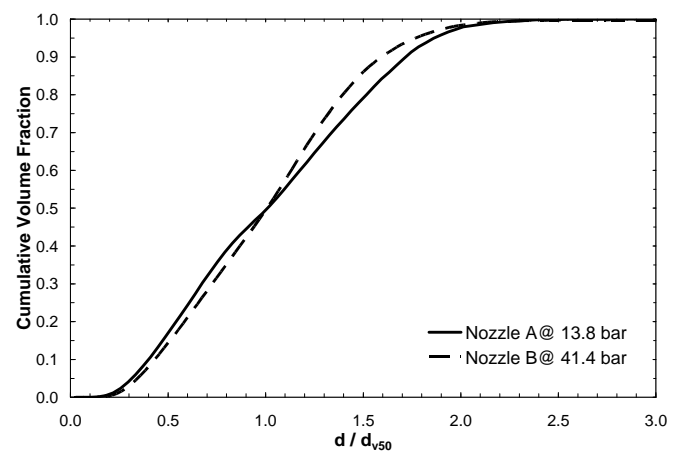

Fig. 3. The gross drop size distributions of A and B nozzles.

temperature inside the drop tube was monitored at two locations using grounded Type-K thermocouples: one at the ceiling center and the other near the right corner of the wall containing the door opening.

\section{Burners and Burner Shields}

A circular burner was used in each enclosure to generate propane fires producing the designated heat release rates. The burners were fabricated with $1.7-\mathrm{mm}$ thick sheet metal, measured $305 \mathrm{~mm}$ diameter and $197 \mathrm{~mm}$ high for the Scale-1 experiments and $914 \mathrm{~mm}$ diameter and $584 \mathrm{~mm}$ high for the Scale-3 experiments. The Scale-3 burner was filled with stones of a few centimeters in diameter in the bottom two thirds of the burner, and small pebbles of about $5 \mathrm{~mm}$ in diameter in the top one third of the burner. For the Scale-1 burner, the entire burner was filled with the small pebbles. Propane, metered with Hasting mass flow meters, was supplied to the burner near the bottom of the burner and was distributed evenly through a ring with holes pointing downwards. The ring was $33 \mathrm{~mm}$ and $102 \mathrm{~mm}$ above the bottom of the burner in the $305-\mathrm{mm}$ and $914-\mathrm{mm}$ burners, respectively. Thermocouples were installed above and inside the burners to monitor the flame temperature and burner temperature.

The burner in each enclosure was protected from water mist spray impingement with a metal shield consisting of a horizontal top cover welded to two opposite walls. The shield for each burner was fabricated with the same sheet metal used to construct the Scale-1 and Scale-3 enclosures. For the Scale-1 burner, the shield's top cover measured $0.41 \times 0.41 \mathrm{~m}$, and each of the vertical walls measured $0.41 \times 0.61 \mathrm{~m}$ high. For the Scale-3 burner, each of the shield's opposite walls measured $1.22 \times 1.83 \mathrm{~m}$ high. Two Type-K thermocouples were used to monitor the shield temperature: one located on the bottom surface at the center of the top cover, and the other on the inside surface (facing the burner) at the center of one of the two shield walls.

\section{EXPERIMENTAL PARAMETERS}

The key experimental parameters are presented in Table 3, in which the values in the parentheses are the ideal values based on the scaling requirements for $\operatorname{Re}_{\mathrm{d}} \leq 1$. The Scale-3 nozzle operating pressure was increased from 41.4 to $43.7 \mathrm{bar}$ in order to obtain the ideal water mist discharge rate scaled up from the Scale-1 rate, i.e. $1.65 \times 3^{2.5}=25.7$. The pressure increase from 41.4 to 43.7 bar also reduced the Scale- $3 \mathrm{~d}_{\mathrm{v} 0.5}$ from 91 to $88 \mu \mathrm{m}$, closer to the ideal drop size of $82 \mu \mathrm{m}$. 
Table 3. Key Experimental Parameters.

\begin{tabular}{|c|c|c|c|c|c|c|}
\hline Scale & $\begin{array}{l}\text { Enclosure Size } \\
\text { (width } x \\
\text { depth } x \\
\text { height) } \\
\text { (m x m x m) }\end{array}$ & $\begin{array}{l}\text { Opening Size } \\
\text { (width } \mathrm{x} \\
\text { height) } \\
\text { (m x m) }\end{array}$ & $\begin{array}{c}\text { Chemical } \\
\text { Heat } \\
\text { Release Rate } \\
(\mathrm{kW})\end{array}$ & $\begin{array}{c}\text { Discharge } \\
\text { Pressure } \\
\text { (bar) }\end{array}$ & $\begin{array}{c}\text { Characteristic } \\
\text { Drop Size } \\
(\mu \mathrm{m})\end{array}$ & $\begin{array}{c}\text { Total Water } \\
\text { Mist } \\
\text { Discharge Rate } \\
\text { (liter } / \mathrm{min} \text { ) }\end{array}$ \\
\hline 1 & $\begin{array}{c}1.22 \times 1.22 \times \\
1.22\end{array}$ & $\begin{array}{l}0.30 \times 0.61 \\
0.61 \times 0.61\end{array}$ & $\begin{array}{c}10,21,30, \\
44\end{array}$ & 13.8 & 62 & 1.65 \\
\hline 3 & $\begin{array}{c}3.66 \times 3.66 \times x \\
3.66\end{array}$ & $\begin{array}{l}0.91 \times 1.83 \\
1.83 \times 1.83 \\
\end{array}$ & $\begin{array}{l}155,330 \\
470,685\end{array}$ & $43.7(41.4)$ & $88(82)$ & 25.7 \\
\hline
\end{tabular}

To investigate the effect of burner location on the experimental results, the burner was either positioned at the center of the enclosure floor or moved from the floor center towards the back wall by half the nozzle spacing. To evaluate the impact of air flow pattern from the door opening to the burner, two burner shield orientations were tested in the experiments. The first orientation was to align the shield's two opposite walls to the door opening, designated as the "block" orientation; the second orientation was to rotate the shield by $90^{\circ}$ so that the two openings of the shield were aligned with the door opening, designated as the "open" orientation.

\section{DATA ANALYSIS}

As water mist is introduced into the enclosure, the heat transfer to the water mist serves to raise its temperature and vaporize water on the mist drop surface. The fire cooling rate by water mist is defined in this study as the rate of total amount of heat transferred from the fire gases to the water mist for mist vaporization. When the experiments are performed under the fire products collector (FPC), the fire cooling rate $\dot{Q}_{\text {cool }}$ by water mist can be expressed by the equation below based on energy balance:

$\dot{Q}_{\text {cool }}=\dot{Q}_{\text {chem }}-\dot{Q}_{\text {conv }}-\dot{Q}_{\text {rad }}-\dot{Q}_{\text {runoff }}-\dot{Q}_{\text {surface }}-\dot{Q}_{\text {duct }}-\dot{Q}_{\text {burner }}$,

where $\dot{\mathrm{Q}}_{\text {chem }}, \dot{\mathrm{Q}}_{\text {conv }}, \dot{\mathrm{Q}}_{\text {rad }}, \dot{\mathrm{Q}}_{\text {runoff }}, \dot{\mathrm{Q}}_{\text {wall }}, \dot{\mathrm{Q}}_{\text {duct }}$, and $\dot{\mathrm{Q}}_{\text {burner }}$ denote fire chemical heat release rate, convective heat flow rate in the FPC, radiative heat loss rate from the enclosure opening, heat loss rate from the run-off water, heat loss rate to the enclosure surfaces, heat loss rate from the FPC gas stream to the FPC duct, and the heat loss rate to the burner and burner shield, respectively.

The chemical heat release rate was calculated from dry-based concentrations of $\mathrm{CO}_{2}$ and $\mathrm{CO}$ and dry-based gas mass flow rate in the FPC. The dry-based mass flow rate was obtained by subtracting the water vapor mass flow rate from the measured mass flow rate in the FPC. In calculating the chemical heat, the heat generation per unit mass production of $\mathrm{CO}_{2}$ and $\mathrm{CO}$ is taken as $15.3 \mathrm{~kJ} / \mathrm{g}$ and $14.0 \mathrm{~kJ} / \mathrm{g}$ [9] for propane fires, respectively. The chemical heat release rate could also be calculated from the measured propane flow rate. With a heat of combustion of $43.7 \mathrm{~kJ} / \mathrm{g}$ for propane [9], the chemical heat release rate measured by the FPC was within $6 \%$ of that based on the propane supply rate during freeburn.

The convective heat flow rate was calculated from the total mass flow rate in the FPC multiplied by the temperature increase of the gas stream relative to the ambient. The water vapor concentration in the FPC was included in determining the specific heat for the gas stream. The measurement uncertainty for the convective heat flow rate in the FPC during water mist application was $8 \%$ and $4 \%$ of the chemical heat release rate for the Scale-1 and Scale-3 experiments, respectively.

The radiative heat loss rate from the enclosure opening was calculated as

$\dot{Q}_{\text {rad }}=\frac{\dot{q}^{\prime \prime} \text { rad }}{F_{1,2}} A_{\text {open }}$,

where $\dot{q}$ "rad is the radiative heat flux measured by the radiometer in front of the door opening, $A_{\text {open }}$ is the door opening area, and $F_{1,2}$ is the view factor between the opening and the radiometer [11]. The value of $\dot{\mathrm{Q}}_{\mathrm{rad}}$ was in general less than $4 \%$ of the fire heat release rate for the experiments conducted in this study. 
As discussed above, the water fractions falling along the enclosure walls and on the floor were drained separately into two buckets and weighed, and the run-off water temperatures were also measured. The sensible heat carried in the run-off water was calculated as

$\dot{Q}_{\text {water }}=\sum \dot{m}_{\text {water }} C_{\text {water }}\left(T_{\text {out }}-T_{\text {in }}\right)$,

where $\dot{m}_{\text {water }}$ is the mass flow rate of the run-off water from the walls or floor, $\mathrm{C}_{\text {water }}$ is the specific heat of water, $T_{\text {out }}$ is the water temperature measured in the U-traps in the drain lines, and $T_{\text {in }}$ is the temperature of discharged water measured in the branch lines. The measurement uncertainty was about $5 \%$.

The total heat loss rate to the enclosure surfaces was calculated by

$\dot{Q}_{\text {surface }}=\sum A_{i} \dot{q}_{\mathrm{i}}^{\prime \prime}$,

where $A_{i}$ is the respective enclosure surface area in which the heat flux $\dot{q}_{i}^{\prime \prime}$ was measured.

The rate of heat lost to the FPC duct wall was the sum of the rate of heat stored in the duct wall and heat loss rate from the duct's outer surface:

$\dot{Q}_{d u c t}=h_{\text {out }} A_{\text {duct }}\left(T_{\text {duct }}-T_{\text {amb }}\right)+m_{\text {duct }} C_{\text {duct }} \frac{d T_{\text {duct }}}{d t}$,

where $\mathrm{h}_{\text {out }}$ is the heat transfer coefficient on the outside surface of the FPC duct, $\mathrm{A}_{\text {duct }}$ is the outside surface area of the duct, $T_{\text {duct }}$ is the duct surface temperature, $T_{a m b}$ is the ambient temperature, $m_{\text {duct }}$ is the mass of the duct, and $\mathrm{C}_{\text {duct }}$ is the specific heat of the duct. The duct segment between the instrumentation station and the top of the gas collection cone was used to determine the duct surface area and mass. Natural convection was assumed on the outer surface of the duct, and $\mathrm{h}_{\text {out }}$ was approximated using the pertinent equations provided in Ref. [12]. Due to the significant cooling of the fire gases by the mist, the heat loss rate to the FPC ductwork during mist application was found to be negligible (less than $1 \%$ of the chemical heat release rate).

The heat loss rate to the burner and the burner shield was calculated by

$\dot{Q}_{\text {burner }}=m_{\text {burner }} C_{\text {burner }} \frac{d T_{\text {burner }}}{d t}+\sum_{i} m_{\text {shield }, i} C_{\text {shield }} \frac{d T_{\text {shield }, i}}{d t}$,

where $\mathrm{m}_{\text {burner }}$ is the burner mass involved in the heat exchange with its surrounding, $\mathrm{C}_{\text {burner }}$ and $\mathrm{C}_{\text {shield }}$ are the specific heats of the burner $\left(0.82 \mathrm{~kJ} / \mathrm{kg} /{ }^{\circ} \mathrm{C}\right)$ and the shield $\left(0.46 \mathrm{~kJ} / \mathrm{kg} /{ }^{\circ} \mathrm{C}\right), \mathrm{T}_{\text {burner }}$ is the average of the burner surface temperature and the temperature at the center of the burner, and $\mathrm{m}_{\text {shield,i }}$ and $\mathrm{T}_{\text {shield, } \mathrm{i}}$ respectively denote the mass and temperature of the shield's top cover and side walls. The heat loss to the burner and the burner shield was found to be small during water mist discharge $(<1 \%$ of the chemical heat release rate).

The less-than-saturated water vapor concentrations measured in the FPC indicated that the possibility of condensation was little in the process of collecting the water-vapor-and-gases mixture flowing out of the enclosure opening. The overall measurement uncertainty of $\dot{Q}_{\text {cool }}$ was estimated to be about $15 \%$.

\section{GENERAL EXPERIMENTAL OBSERVATIONS}

Figure 4 shows an example of the data traces of chemical heat release rate, convective heat flow rate measured in the FPC, the enclosure interior temperature measured with the thermocouple tree and the enclosure oxygen concentration obtained from two Scale-3 experiments conducted with different door opening sizes. In these two experiments, the burner was located at the floor center, the burner shield was in the open orientation, and the nominal fire heat release rate was $700 \mathrm{~kW}$. The graphs on the left and on the right in Fig. 4 pertain to the door openings of $1.83 \times 1.83 \mathrm{~m}$ and $0.91 \times 1.83 \mathrm{~m}$ high, respectively. The water mist discharge was started about 240 seconds after ignition. The fire was not extinguished in the test conducted with the $1.83 \times 1.83$ m opening, which was terminated at about 1080 seconds from the ignition. On the other hand, in the test conducted with the $0.91 \times 1.83 \mathrm{~m}$ high opening, the fire was extinguished at about 190 seconds after the start of water mist discharge. As shown, the mean chemical heat release rate before and during water mist application was comparable in these two tests. The convective heat flow rate 
decreased from the pre-discharge level due to water mist cooling. The relatively uniform temperature readings, close to wet-bulb temperatures due to mist wetting, from the thermocouple tree during water mist application indicate that the fire gases in the enclosure were reasonably well mixed by the sprays. The floor-level oxygen concentration stayed at the ambient level until the sprays were started. However, the overall enclosure oxygen concentration decreased shortly after the fire was started in the enclosure. The close agreement between the floor-level concentration and the overall concentration during water mist application provides another indication that the enclosure fire gases were well mixed in these experiments.

Figure 4 also re-affirms the positive impact of opening reduction on fire extinguishment. As the enclosure opening becomes smaller, the gas inflow and outflow in, and the radiative heat loss through, the opening decreases. This results in a worse vitiation condition and a higher overall gas temperature in the enclosure to enhance mist vaporization. As a result, the oxygen concentration in the enclosure may be lowered to such an extent that the flame can no longer sustain itself.

With the experimental parameters used in the present investigation, the effect of water mist application on the fire could be reasonably reproduced between the Scale-1 and Scale-3 experiments. In general, the propensity of fire extinction increased as 1) the enclosure opening size was reduced; 2) the burner was moved away from the door opening; and 3) the burner shield was in the block orientation. The opening-size effect is just described above. As the burner is moved away from the door opening, the air current from the door opening to the burner was subjected to greater interference by the downward water mist sprays between the door opening and the burner. The burner shield in the block orientation hindered the direct access of ambient air flow from the door opening to the burner. Therefore, all the above three conditions tended to reduce the oxygen level in the vicinity of the burner, thus increase the likelihood of fire extinction.
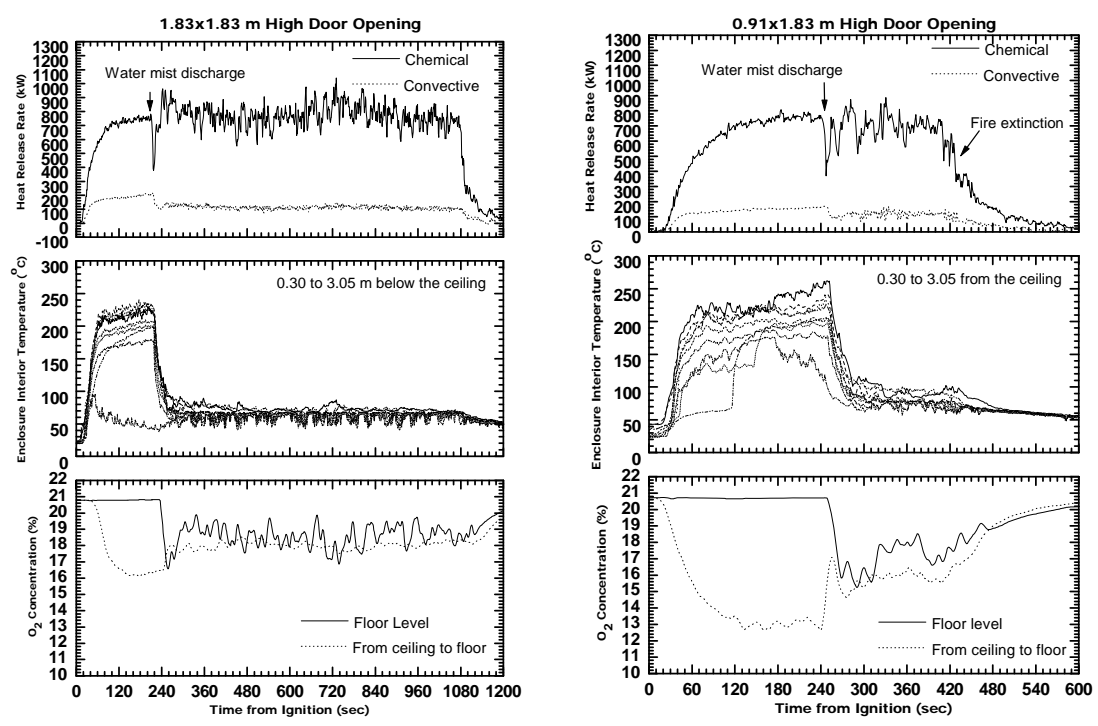

Fig. 4. An illustration of data traces obtained from two Scale-3 experiments. The common test conditions are: 1) burner was on the floor center; 2) burner shield was in the open orientation; and 3) the nominal fire heat release rate was $700 \mathrm{~kW}$. The graph on the left pertains to the $1.83 \times 1.83 \mathrm{~m}$ high door opening and the graph on the right is for the $0.91 \times 1.83 \mathrm{~m}$ high door opening.

\section{SCALABILITY OF FIRE COOLING RATES}

As shown in Table 1, the scaling law indicates that the fire cooling rate by water mist sprays is scaled with 5/2-power of the scale ratio. As recalled, Froude modeling does not account for the effects of solid boundaries on the amount of fire heat release rate retained in the control volume for heating and vaporizing water drops.

When the fire is enclosed, the radiant heat loss to the ambient is insignificant if the openings communicating to the ambient are a small fraction of the total enclosure surface area. For instance, the door 
opening areas in the present experiments are no more than $4.2 \%$ of the enclosure surface area. Therefore, besides the convection through the door opening, the heat loss from the enclosure control volume is mainly through the radiative and convective heat transfer to the enclosure walls, ceiling and floor. If the total fire heat release rates are scaled with 5/2-power of scale ratio, to have the amount of net heat input into the enclosure volume stay reasonably true to the same scaling requirement, the total heat loss rate to the enclosure surfaces has to remain equal to a constant fraction of the fire heat release rates in different model scales. In the present experiments, the heat loss to the enclosure surfaces during water mist discharge was insignificant relative to the fire heat release rate because the thermal environment in the enclosure was extremely uniform under water mist applications. As a result, the net heat inputs into the two tested enclosures could also be closely scaled to the 5/2-power of the scale ratio during the water mist application period. Therefore, the total (chemical) fire heat release rate is an appropriate parameter to correlate with the water mist cooling of enclosure fires.

By reducing the enclosure opening size or increasing the fire intensity, a higher enclosure gas temperature can be obtained. Under the same water mist application condition, the increase of enclosure gas temperature increases the water mist vaporization rate and therefore the fire cooling rate. With this expectation, the fire-cooling-rate data are presented in Fig. 5 separately for the larger (the graph on the left) and smaller (the graph on the right) door opening situations for both the Scale-1 and Scale-3 experiments.

To evaluate the scalability of the fire cooling rates obtained from the Scale- 1 and Scale-3 experiments, both the fire chemical heat release rates and corresponding cooling rates are normalized with $S^{5 / 2}$ in Fig. 5. In addition to the fire cooling rate data obtained from experiments in which the fire could persist indefinitely under the water mist application (in closed symbols), Fig. 5 also include the data of the experiments in which fire extinction occurred (in open symbols), as long as a reasonably long steady-state duration was available for data averaging before fire extinction. As shown, the degree of data scatter of $\dot{Q}_{\text {cool }} / S^{5 / 2}$ is about $\pm 13 \%$ in the entire range of $\dot{Q}_{a} / S^{5 / 2}$ used in the present experiments. The reasonably good agreement between the Scale-1 and the Scale-3 results shows that the fire cooling by water mist applications can be scaled for propane fires situated in enclosures, which is insensitive to burner location and burner shield orientation. However, as mentioned above, both burner location and shield orientation would tend to influence the fire extinguishment result. The regression of the fire-cooling-rate data presented in Fig. 5 for the larger and smaller door openings used in the Scale-1 and Scale-3 experiments can be expressed with

$\dot{Q}_{\text {cool }} / S^{5 / 2}=0.718 \dot{Q}_{a} / S^{5 / 2}$ and $\dot{Q}_{\text {cool }} / S^{5 / 2}=0.771 \dot{Q}_{a} / S^{5 / 2}$,
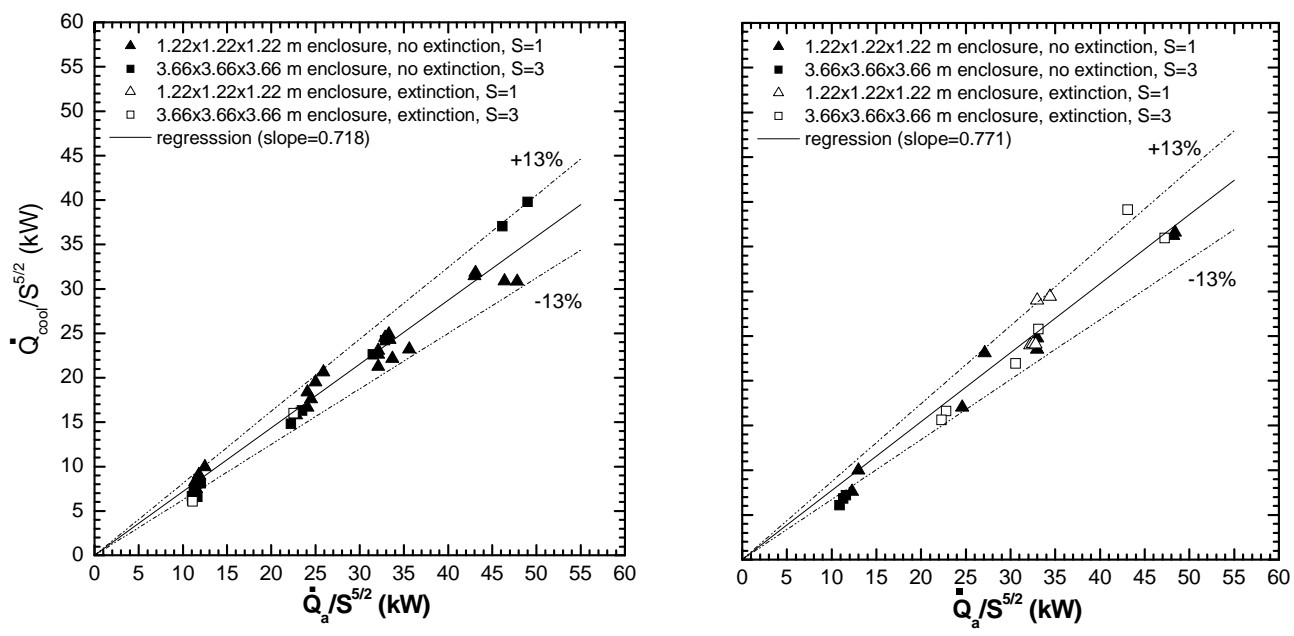

Fig. 5. Scaled fire cooling rates of the Scale-1 (triangles) and Scale-3 (squares) experiments for the larger door openings (the graph on the left) and the smaller door openings (the graph on the right). Closed symbols represent the data obtained from tests in which the fire could persist indefinitely; open symbols represent the tests in which fire extinction occurred. 
respectively. The greater regression slope for the smaller door openings is consistent with the expectation that the fire cooling rate will be higher as the enclosure gas temperature is increased by restricting the enclosure ventilation.

\section{CONCLUSION}

A series of fire suppression experiments was conducted in two geometrically similar enclosures of 3-to-1 scale ratio under fire products collectors to quantify water mist cooling of propane fires, to evaluate the applicability of Froude modeling of water mist fire suppression in enclosures. The parameters considered in the evaluation were: enclosure size, door opening size, water mist spray condition, fire size, fire location and fire-shielding condition. The results show that water mist cooling of enclosure fires can be scaled as expected. This favorable conclusion holds promise for the use of physical modeling in the evaluation of water mist protection solutions.

\section{REFERENCES}

[1] Liu, Z. and Kim, A.K., (2000) A Review of Water Mist Fire Suppression Systems - Fundamental Studies, Fire Protection Engineering 10(3):32-50.

[2] Jones, A. and Nolan, P.F., (1995) Discussions on the use of fine water sprays or mists for fire suppression, Loss Prevention in the Process Industries 8(1):17-22. doi:10.1016/0950$\underline{4230(95) 90057-\mathrm{V}}$

[3] Liu, A. and Kim, A.K., (2001) A Review of Water Mist Fire Suppression Technology: Part II Application Studies, Fire Protection Engineering 11(1):16-42.

[4] Back, G.G., Beyler, C.L., DiNenno, P.J., and Hansen, R., "Water Mist Protection Requirements for Very Large Machinery Spaces," U.S. Coast Guard Research and Development Center Report CG-D-15-00, Groton, CT, 2000.

[5] Heskestad, G., (1975) Physical Modeling of Fire, Fire \& Flammability 6:254-273.

[6] Yu, H-Z, "Froude-Modeling-Based General Scaling Relationships for Water-Spray-Fire-Plume Interactions," Fire Safety Science - Proceedings of $7^{\text {th }}$ Asia-Oceania Symposium on Fire Science and Technology, International Association of Fire Safety Science, 2007.

[7] Jayaweera, T.M. and Yu, H-Z, (2008) Scaling of fire cooling by water mist under low drop Reynolds number conditions, Fire Safety Journal 43(1):63-70. doi:10.1016/j.firesaf.2007.01.004

[8] Croce P.A., (1976) A method for improved measurement of gas concentration histories in rapidly developing fires, Combustion Science and Technology 14:221-228. doi: $10.1080 / 00102207608547530$

[9] Tewarson A., "Generation of heat and chemical compounds in fires," The SFPE Handbook of Fire Protection Engineering (3rd ed), DiNenno P.J. (ed.), National Fire Protection Association, Quincy, MA 02269, 2002, p. 3/82.

[10] Ditch, D.D. and Yu, H-Z, "Characterization of Water Mist Sprays Using a Phase-DopplerParticle-Analyzer and Iso-Kinetic Sampling Probe," Proceedings of HTFED 2004, American Society of Mechanical Engineers, July 11-15, 2004, Charlotte, North Carolina, USA.

[11] Siegel, R., and Howell, J.R., Thermal Radiation Heat Transfer, $2^{\text {nd }}$ ed, Hemisphere Publishing Corp., 1981.

[12] Incropera, F.P. and DeWitt D.P., Introduction to Heat Transfer, $3^{\text {rd }}$ ed, John Wiley \& Sons, 1996. 